\title{
Discrete Element Simulation Analysis of the Bending and Toppling Failure Mechanisms of High Rock Slopes
}

\author{
Zhigang Meng, ${ }^{1,2,3}$ Yongli Hou, ${ }^{1,4}$ Longji Guo, ${ }^{2}$ Fengnian Wang $\mathbb{D}^{2}{ }^{2}$ Kuiming Liu $\mathbb{D}^{2},{ }^{2}$ Gan Qi, ${ }^{5}$ \\ and Juan $\mathrm{Ma}^{5}$ \\ ${ }^{1}$ Liaoning Non-Ferrous Geological Exploration and Research Institute Co., Ltd., Shenyang 110000, China \\ ${ }^{2}$ School of Mechanics and Civil Engineering, China University of Mining \& Technology, Beijing 100083, China \\ ${ }^{3}$ State Key Laboratory for Geomechanics \& Deep Underground Engineering, China University of Mining \& Technology, \\ Beijing 100083, China \\ ${ }^{4}$ Technology Innovation Center of Old Mine Geological Disaster Prevention and Ecological Restoration Engineering, Ministry of \\ Natural Resources, Beijing 100083, China \\ ${ }^{5}$ China Geological Environmental Monitoring Institute, Beijing 100081, China
}

Correspondence should be addressed to Kuiming Liu; 369934321@qq.com

Received 10 December 2020; Revised 4 January 2021; Accepted 22 January 2021; Published 31 January 2021

Academic Editor: Feng Xiong

Copyright (C) 2021 Zhigang Meng et al. This is an open access article distributed under the Creative Commons Attribution License, which permits unrestricted use, distribution, and reproduction in any medium, provided the original work is properly cited.

\begin{abstract}
The high rock slope situated in the Southwest stope of Taiping Mining, Inner Mongolia, is subject to dumping failure due to its instability. The dumping body rock layer of this stope shows obvious bending and lowering of the head. The overturning angle of the rock strata can reach $46^{\circ}$, and tension dislocation along the rock joint can be observed in exposed sections and at the bedding and lithologic interface. The sliding surface also displays a broken line morphology. Through evaluation of regional rock integrity parameters and rock soft and hard parameters, rock-mass strength based on Hoek Brown strength estimation criteria can be developed. Based on the discrete element method, the geological model of layered excavation of the thin layer slope can be constructed. Combined with indoor and outdoor assessments, the characteristics of toppling deformation of the thin layer open-air slope can be studied and summarized. In this study, simulation analysis showed that under first excavation conditions, a crack-, dump-, and antislip zone was formed. The rock in the crack zone formed a "<"-shaped fracture along the slope surface that was squeezed towards the bottom of the slope. In the lower dumping area, the deflection angle gradually increased with excavation, and the deformation range and levels in the antislip area increased with excavation. Following the third excavation, the antisliding zone disappeared and the toppling line changed from a broken line to a straight line. In the final state, the slope collapsed as a whole, with the collapse of the dumping body penetrating the top to the foot of the slope.
\end{abstract}

\section{Introduction}

Rock slope dumping failure [1-15] is a major cause of instability in the engineering of rock slopes. With increasing construction activities such as mining, hydropower development, roads, and bridges in areas such as the Jinchuan open-pit mine, the Santan dam site of the Jingping Hydropower Station on the Yalong River, the left bank of the hydrological station dam site, and the right abutment of the Kutiao Valley dam site of the Hutiaoxia Hydropower Station [16], rock slope dumping failure remains an issue. Through rock slope toppling failure case studies, it can be concluded that rock slope toppling is controlled by the structural planes of the slope, including internal faults, fissures, layers, and joints. The structural surface of the dumping rock slope harbors a rock layer and slope surface with similar trends, but opposite tendencies, leading to "head bowing" [17, 18]. According to the characteristics of rock slope toppling failure [19], Yang et al. [20] used an improved transfer coefficient method based on the geomechanical model of the rock slope and proposed an analytical method for the rock slope sliding-topping. Amini et al. [21] considered the deformation coordination conditions of adjacent rock formations and deduced a formula describing dumping safety based on the interaction between the rock formation and the position of 


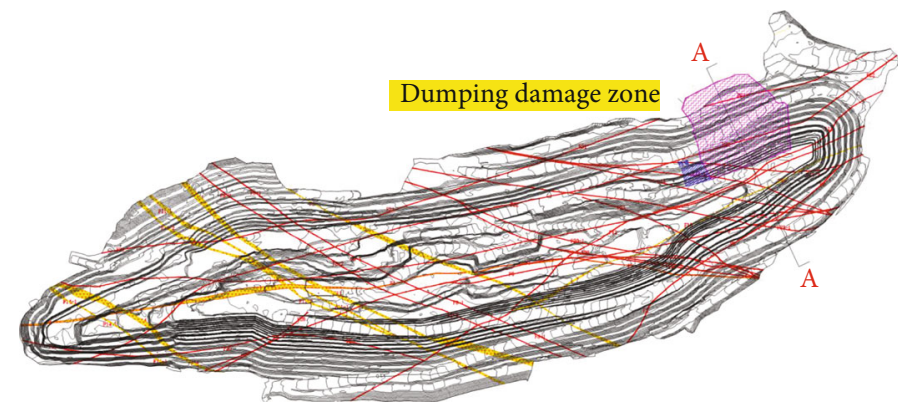

FIgURE 1: Distribution of fault-cutting and destruction zones in the Southwest stope.

the action point. Majdi and Amini [22] considered the influence of cracks in the rock formation and used the theory of fracture mechanics to improve the method proposed by Amini and colleagues. Based on the stress criterion, Chen and Huang [23] proposed the deflection criterion of bending fractures, whilst Cai et al. [24] used the discrete element method (UDEC) to simulate and analyze the failure characteristics of slope bending and toppling, discussing the factors influencing slope stability. Haghgouei et al. [25] established an analytical method to improve understanding of the failure mechanism of "overfall landslide" and proposed several designs to determine the anticollapse failure mechanism of the slope. Dong et al. [26] simulated the development process of dumping deformation and failure through similar tests and summarized six stages of the dumping process, systematically analyzing the relationship between displacement time and stress strain during the deformation process. Li et al. [27] studied the composite mobilization surface using strain energy and improved the composite mobilization surface model. The yield strain energy and strength criterion can therefore be established using different combinations of stress variables.

Current theoretical studies of antidipping rock slopes [28-32] are challenging to apply due to the complexity of the analytical process. This can be overcome through computer modeling combined with indoor and outdoor survey data, which represents a growing trend in studies of the dumping slope. Numerous analysis methods exist, with different advantages and limitations. Different slope types also require corresponding finite element methods, which can be limited by the failure characteristics of highly discontinuous dumping. The discrete element method [33-46] differs from the finite element method, which due to its advantages in simulating the discontinuous characteristics of the discrete medium describe mechanical behaviors such as shear rolling or disconnection between the rock blocks (continuous body) and geological structural planes (discontinuous features). These are particularly suitable for studies of mass deformation or the failure process.

In this study, based on the discrete element method, a geological model of the thin layer slope in the Taiping Mining open-pit gold mine was established. Combined with indoor and outdoor assessments, the regularity of toppling deformation of the thin layer open-air slope was studied and summarized. A failure law in response to continual mining was also described, providing future reference for slope design.

\section{Geological Characteristics}

2.1. Site Engineering. The Open-pit Gold Mine of Taiping is located $85^{\circ}$ Northeast of the Urad Middle Banner in the Inner Mongolia Autonomous Region. This area is a low-mountain, hilly terrain, with an elevation of $1550-1750 \mathrm{~m}$ and a relative elevation difference of 50-200 m. The core bodies are mainly distributed in low-lying areas. The open pit can be divided into Northeast and Southwest slopes. The geological structure in the area is complex, with multiple fault fracture zones running through the stope from East to West. Controlled by the structure, the integrity of the slope rock in the stope is poor. The stability of the rock has also been weakened. Geological disasters such as local landslides, collapses, and dumping deformation are common in this region during mining.

The exposed strata from old to new in this area are as follows: the Middle Proterozoic Bayan Obo Group dulahala formation (Pt2byd), Jianshan rock formation (Pt2byj), halahoete rock (Pt2byh), and birut rock formation (Pt2bybb); the middle upper Jurassic bainuyangpan volcanic rock formation (J2-3b3) and tertiary Pliocene (N2). The dumping failure area is located in the north side of the southwest stope. The scope and geological section of the failure area are shown in Figures 1 and 2. The main lithology includes quaternary overburden $(\mathrm{Q})$, gneisserite (B3-3), andalusite schist (B3-2 and B2-1), tapered-sandstone (B3-1 and B1), and erdolite quartz schist (B2-2).

\subsection{Failure Characteristics of the Toppling Body}

2.2.1. Overview of the Damaged Area. On April 30, 2017, a large area of dumping damage occurred on the North-side of the Southwest stope. The damaged area was located at the east $U$ mouth of the North side of the Southwest stope. The dumping slope was an antidip slope. Affected by this landslide, the step and transportation road were completely abandoned, and mining operations at the lower area were ceased. A large area of fracture occurred in the middle of the failure zone, and local rock masses became bent and toppled. The location of the failure is shown in Figures 1 and 3. The dip angle of the rock stratum forms an $85^{\circ}$ inverted structure, and the distribution density of joints and fissures occurs between 7 and 15 strips $/ \mathrm{m}$. The width of the joints in the West and East areas is relatively large. Some boundaries, faults, and cracks exist which are present at exposed areas of the steps. 


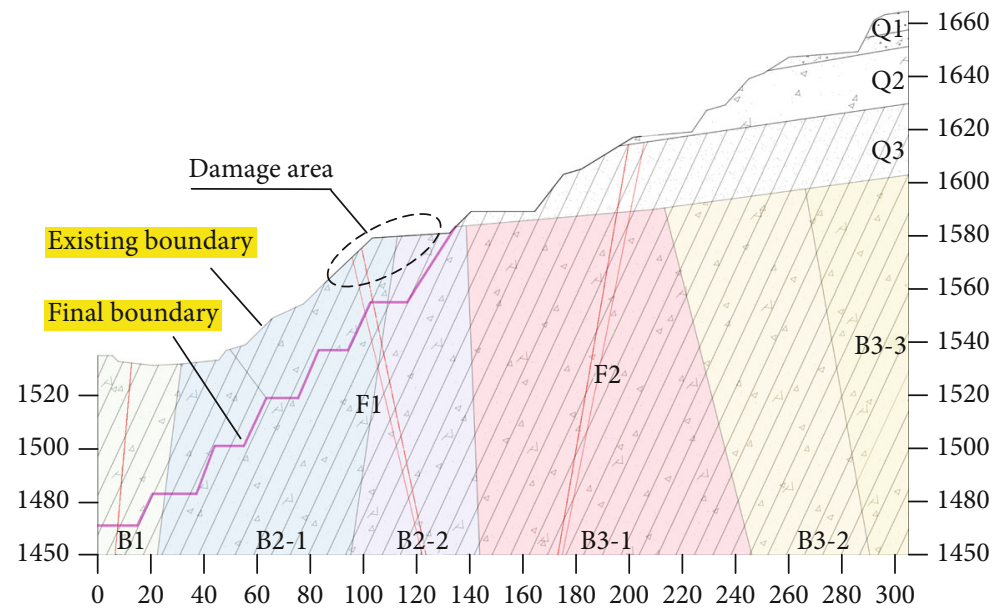

FIgUre 2: Typical A-A failure section of the Southwest stope.

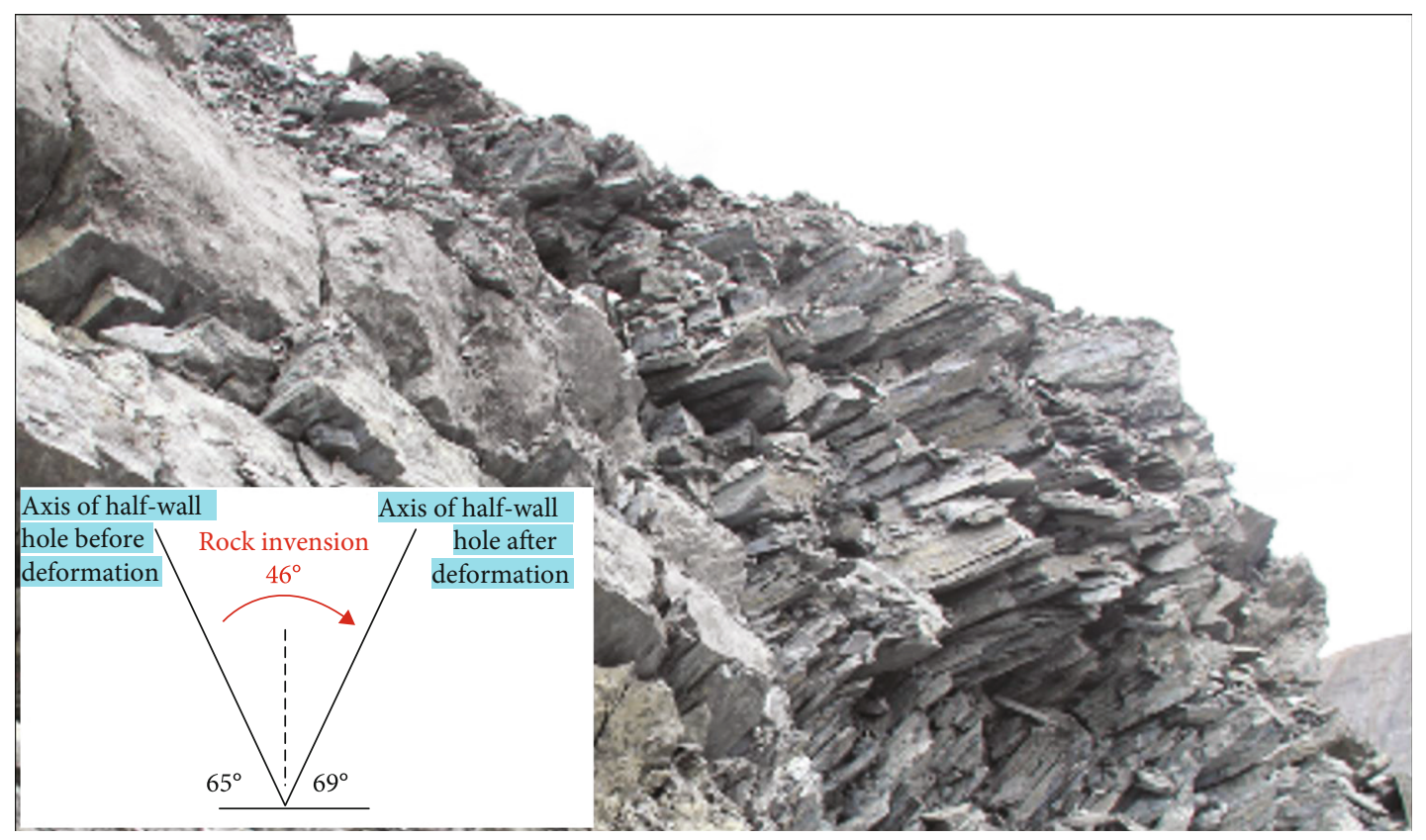

FIgURe 3: Typical cross section of mining pit [28].

2.2.2. Rock Mass Dip Variation in the Failure Zone. Slope excavation uses a drilling and blasting method, with evident half-wall holes left over from the excavation face. By measuring the deflection angle of the half-wall hole on the slope surface, the original inclination angle was found to be $65^{\circ}$. The inclination angle following rotating and deformation of the dumping rock layer was $-69^{\circ}$, proving that the rock layer dumped and turned $46^{\circ}$. The deflection is shown in Figure 3.

2.2.3. Characteristics of Rock Toppling and Pulling Cracks. Due to the bending and toppling of the rock strata, the slat plane, the interlaminar weak zone, and the interlaminar fault produce tension and dislocation, forming wedge tensioning, cracks, and rock fracturing. In slate, sandstone, and other

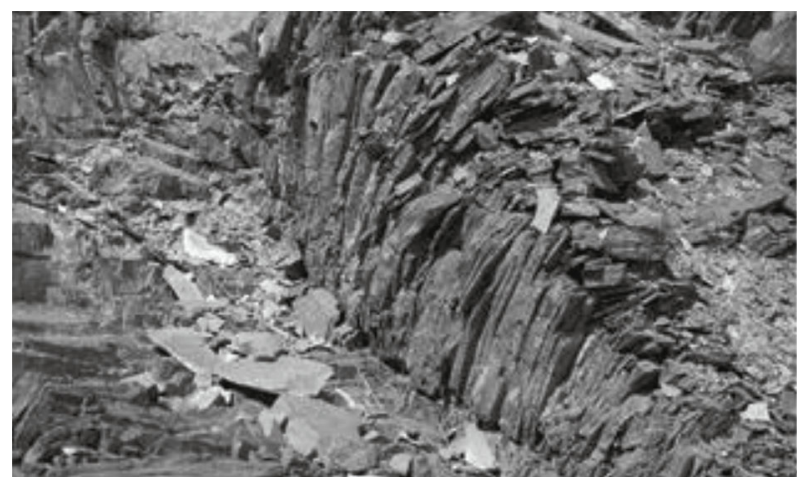

FIgURE 4: Typical cross-section of the mining pit. 
TABLE 1: Average spacing of the structural planes.

\begin{tabular}{lccccc}
\hline Sample & $\begin{array}{c}\text { Natural density } \\
\left(\mathrm{g} / \mathrm{cm}^{3}\right)\end{array}$ & $\begin{array}{c}\text { Compressive strength } \\
(\mathrm{MPa})\end{array}$ & $\begin{array}{c}\text { Elastic modulus } \\
(\mathrm{MPa})\end{array}$ & $\begin{array}{c}\text { Internal friction angle } \\
\left({ }^{\circ}\right)\end{array}$ & $\begin{array}{c}\text { Poisson's } \\
\text { ratio }\end{array}$ \\
\hline Gneiss & 2.67 & 152.4 & 74.0 & 58.9 & 0.11 \\
Andalusite schist & 2.81 & 102.6 & 26.9 & 57.4 & 0.17 \\
$\begin{array}{l}\text { Thinned } \\
\text { sandstone }\end{array}$ & 2.90 & 123.9 & 40.9 & 60.8 & 0.25 \\
Quartz schist & 2.75 & 183.0 & 34.5 & 56.9 & 0.18 \\
\hline
\end{tabular}

TABLE 2: Average spacing of the structural planes.

\begin{tabular}{lcccccccc}
\hline \multirow{2}{*}{ Lithology } & & \multicolumn{4}{c}{ Mineral species and content (\%) } & \multicolumn{2}{c}{ Total amount of } \\
& Quartz & Potassium feldspar & Plagioclase & Calcite & Dolomite & Pyrite & Ordinary pyroxene & clay minerals (\%) \\
\hline Gneiss & 66.2 & $/$ & 12.7 & 16.9 & $/$ & 2.3 & $/$ & 1.9 \\
Andalusite schist & 59.0 & $/$ & 3.3 & 26.3 & $/$ & $/$ & $/$ & 11.4 \\
Thinned-sandstone & 8.9 & 3.6 & 3.0 & 66.5 & 1.9 & $/$ & 15.0 & 1.1 \\
Quartz schist & 46.5 & 0.7 & 32.5 & 19.8 & $/$ & $/$ & $/$ & 0.5 \\
\hline
\end{tabular}

areas undergoing changes in lithology, tension fracture zones were formed (Figure 4).

2.2.4. Features of Falling and Fracture of the Sliding Surface. The toppling surface represents the potential sliding surface of the landslide body. The deepest point of the buried surface is approximately $20 \mathrm{~m}$. The sliding surface (toppling bending surface) forms an arc of the concave surface, with the tangential dip angle of the upper arc being $43^{\circ}$ and the tangential dip angle of the lower arc being $14^{\circ}$, with an average angle of $29^{\circ}$.

\section{Rock Mechanics}

3.1. Basic Mechanical Characteristics. By sampling representative and comparable on-site rock samples, physical and mechanical tests were performed. In total, 27 samples were collected, including 7 granite, 5 slate, 2 quartz sandstone, 7 mica schists (including two different bedding tendencies), 3 andalusite schist, and 3 fine sandstone samples. Visible cracks were visible in some granite and quartz sandstone specimens with a size of $50 \mathrm{~mm} \times 100 \mathrm{~mm}$. Basic physical parameters are shown in Table 1.

3.2. Mineral Composition. The mineral composition of the rock indirectly dictates its physical and mechanical properties. Mineral composition can describe the regularity of rock strength at the material level. Samples of representative rock formations were selected for whole-rock mineral composition analysis (Table 2). From the perspective of mineral composition, the overall rock clay mineral content in this area is low. Excluding andalusite schist exceeding 10\%, the rest remain less than $5 \%$. The quartz content of the schist and slate was high, which also explains the high strength and low degree of weathering of the rock blocks.

3.3. Microstructural Characteristics. From a macroscopic standpoint, the rock mass of the mine shows an obvious layered structure which undoubtedly controls slope deformation. Through SEM scanning, this layered structure can be imaged at the microscopic level. As shown in Figure 5, SEM analysis was performed on 5 samples of gneiss, andalusite schist, fine sandstone, and quartz schist.

Upon analysis (Figure 5), the gneiss rock samples showed obvious dense and lamellar bedding. The microfracture of andalusite schist was obvious, and the internal structure was relatively broken and discontinuous. The surface of the thinned sandstone was compact and smooth, without obvious foliation or fine grain density. The Quartz schist has obvious physicochemical characteristics and fractures in the schist.

Upon analysis, the majority of rock masses in this area showed an obvious layered structure that ranged from macroscopic to microscopic, forming layered or flaky structures. The regional structure of the rock and slope mass from micro-cross-sections showed morphological similarities, which were a direct product of the complex geological structure in this area. This also shows that the area suffered severe horizontal tectonic movement compression. These layered structural features of different scales represent objective conditions controlling the law of slope excavation deformation.

3.4. Transformation of Physical and Mechanical Parameters of the Rock Mass. Field investigations and laboratory test analyses showed that the strength of each type of rock in the area was hard and that the collapse of the stope slope was mainly controlled by the structural surface of the rock mass. It is therefore necessary to estimate the strength of the rock mass during engineering evaluations and design to perform numerical analysis and the evaluation of slope stability. The Hoek-Brown intensity estimation criterion was proposed in 1980 and has since been revised several times $[47,48]$. To date, most geotechnical engineering software is compiled based on the Mohr Coulomb criterion in which the strength of the rock mass is characterized by the cohesion $c$ and internal friction angle $\varphi$. In view of this situation, Hoek proposed the corresponding rock mass strength estimation method in 2002 [49-51]. In this study, based on this 


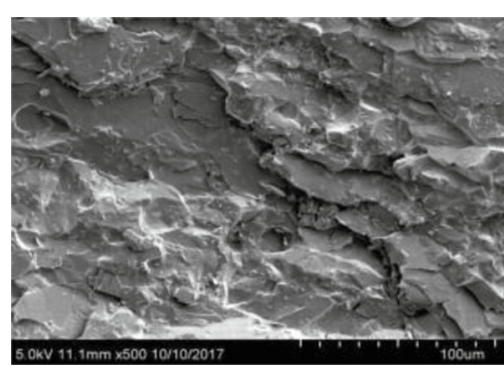

(a) Gneiss $(\times 500)$

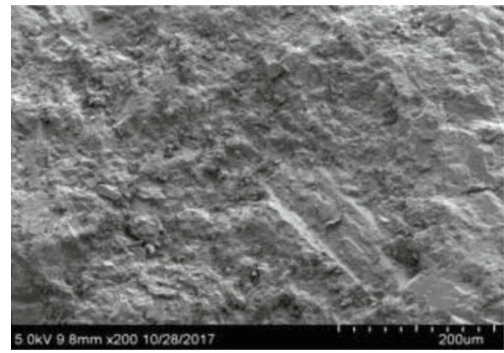

(c) Thinned sandstone $(\times 200)$

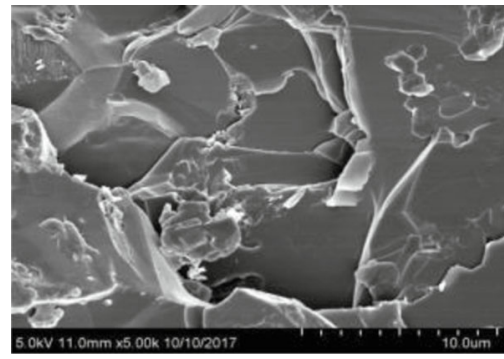

(e) Gneiss ( $\times 5 \mathrm{k})$

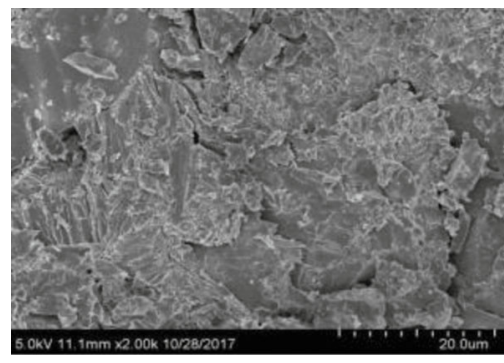

(g) Thinned sandstone $(\times 2 \mathrm{k})$

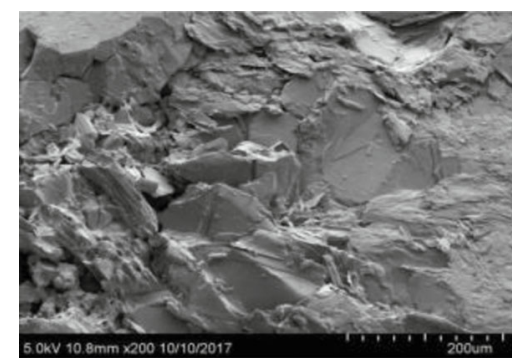

(b) Andalusite schist $(\times 200)$

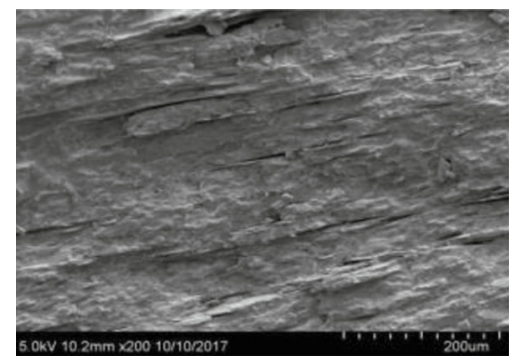

(d) Quartz schist $(\times 200)$

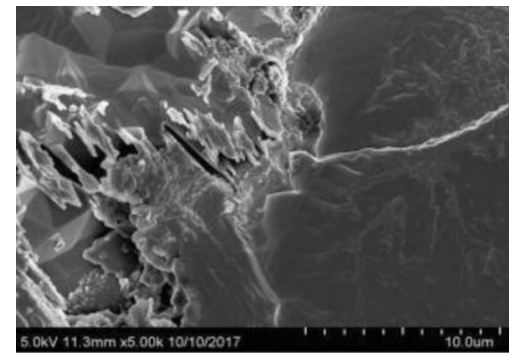

(f) Andalusite schist $(\times 5 \mathrm{k})$

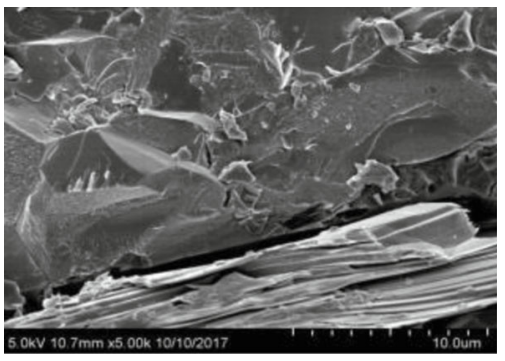

(h) Quartz schist ( $\times 5 \mathrm{k})$

FIGURE 5: SEM images of different rock samples.

TABLE 3: Hoek-Brown criterion for estimating slope strength parameters.

\begin{tabular}{|c|c|c|c|c|c|c|c|c|c|c|c|}
\hline \multirow[t]{2}{*}{ Lithology } & \multicolumn{4}{|c|}{$\begin{array}{l}\text { Basic variables of Hoek Brown } \\
\text { criterion }\end{array}$} & \multicolumn{5}{|c|}{$\begin{array}{c}\text { Intermediate variable of Hoek Brown } \\
\text { criterion }\end{array}$} & \multicolumn{2}{|c|}{ Estimated value } \\
\hline & $\sigma_{c}$ & GSI & $m_{i}$ & $D$ & $m_{b}$ & $\alpha$ & $s$ & $\sigma_{c m}$ & $\sigma_{3 n}$ & $\varphi\left(^{\circ}\right)$ & $C(\mathrm{MPa})$ \\
\hline Gneiss & 152.40 & 40.00 & 3.00 & 0.30 & 0.2411 & 0.5114 & 0.0006 & 9.6728 & 0.0268 & 31.5267 & 1.1078 \\
\hline Andalusite s & 102.60 & 40.00 & 3.00 & 0.30 & 0.2411 & 0.5114 & 0.0006 & 6.5120 & 0.0180 & 34.4629 & 0.6381 \\
\hline Thinned sandston & 123.90 & 40.00 & 3.00 & 0.30 & 0.2411 & 0.5114 & 0.0006 & 7.8639 & 0.0218 & 33.0715 & 0.8273 \\
\hline Quartz schist & 183.00 & 40.00 & 3.00 & 0.30 & 0.2411 & 0.5114 & 0.0006 & 11.6150 & 0.0322 & 30.1540 & 1.4418 \\
\hline
\end{tabular}


criterion, the strength parameters of the high rock slope in this area were estimated and analyzed. Using $\sigma_{c}, m_{i}$, GSI, and $D$ as basic variables, the evaluation equations of the rock mass parameters were established as follows:

$$
\begin{aligned}
& \varphi=\sin ^{-1}\left[\frac{6 \alpha m_{b}\left(s+m_{b}\right)^{\alpha-1}}{2(1+\alpha)(2+\alpha)+6 \alpha m_{b}\left(s+m_{b} \sigma_{3 n}\right)^{\alpha-1}}\right], \\
& c=\frac{\sigma_{c}\left[(1+2 \alpha) s+(1-\alpha) m_{b} \sigma_{3 n}\right]\left(s+m_{b} \sigma_{3 n}\right)^{\alpha-1}}{(1+\alpha)(2+\alpha) \sqrt{1+\left[6 \alpha m_{b}\left(s+m_{b} \sigma_{3 n}\right)^{\alpha-1}\right] /[(1+\alpha)(2+\alpha)]}} .
\end{aligned}
$$

The variables $m_{b}, \alpha, s, \sigma_{\text {an }}$ and $\sigma_{3 n}$ can be obtained from the following equations using the basic variables:

$$
\begin{aligned}
m_{b} & =m_{i} \exp \left[\frac{\mathrm{GSI}-100}{28-14 D}\right], \\
\alpha & =\frac{1}{2}+\frac{1}{6}\left(e^{-\mathrm{GSI} / 15}-e^{-20 / 3}\right), \\
s & =\exp \left(\frac{\mathrm{GSI}-100}{9-3 D}\right) \\
\sigma_{3 n} & =\frac{\sigma_{3 \max }}{\sigma_{c m}}=0.72\left[\frac{\sigma_{c m}}{\gamma H}\right]^{-0.91}, \\
\sigma_{c m} & =\sigma_{c} \frac{\left[m_{b}+4 s-\alpha\left(m_{b}-8 s\right)\right]\left(m_{b} /(4+s)\right)^{\alpha-1}}{2(1+\alpha)(2+\alpha)}
\end{aligned}
$$

According to the survey analysis, the slope height of the survey area was $\sim 100-120 \mathrm{~m}$, so the $H$ value was $110 \mathrm{~m}$, the rock mass quality was mainly Grade III, and the GIS statistics were 40.

$D$ represents the disturbance parameters considering the blasting effects and stress release (value range of $D$ is $0.0 \sim 1.0$, undisturbed rock mass is 0.0 , and extremely disturbed rock mass is 1.0); according to the influence of rock excavation and blasting vibration, the rock mass correction variable $D$ is taken as $0.8 ; m_{i}$ is a dimensionless empirical parameter, which reflects the degree of hardness and softness of the rock. The value ranges from 0.001 to 25.0 . According to the $m_{i}$ value proposed by Hoek, the $m_{i}$ value of mixed metamorphic rocks in this area can be taken as 3 .

According to uniaxial strength data obtained from indoor test results, the strength parameters of the slope rock mass in this area can be estimated and analyzed using Hoek Brown criterion. These analyses are shown in Table 3.

\section{Discrete Element Simulation}

4.1. Principles of Discrete Simulation of the Rock Mass Element. 3DEC is a 3D simulation software based on the discrete model Lagrangian finite difference algorithm. During

\begin{tabular}{|c|c|c|c|}
\hline Lithology & Codename & $\begin{array}{l}\text { Average spacing } \\
\text { (m/article })\end{array}$ & $\begin{array}{l}\text { Linear density } \\
\text { (m/article) }\end{array}$ \\
\hline Gneiss & B3-3 & 0.51 & 1.96 \\
\hline $\begin{array}{l}\text { Andalusite } \\
\text { schist }\end{array}$ & $\begin{array}{l}\text { B3-2 and } \\
\text { B2-1 }\end{array}$ & 0.32 & 3.12 \\
\hline $\begin{array}{l}\text { Thinned } \\
\text { sandstone }\end{array}$ & $\begin{array}{c}\text { B1 and } \\
\text { B3-1 }\end{array}$ & 0.44 & 2.27 \\
\hline Quartz schist & B2-2 & 0.22 & 4.55 \\
\hline
\end{tabular}
calculations, the rock mass medium is regarded as a set of discrete blocks, with the discontinuity between blocks regarded as the boundary condition, allowing large deformation and block rotation along the discontinuous surface. A single rock block can be rigid or elastic and is defined by tet-
TABLE 4: Average spacing of the structural planes.

rahedral finite-difference elements, with each subdivided element body responding to prescribed linear or nonlinear constitutive models.

When shear stress on the joint surface exceeds its shear strength, shear deformation will occur on the joint surface, so that the stress-strain field of the slope can be adjusted, thus affecting the deformation and failure behavior of the entire slope.

4.2. Geological Model and Parameters. The geological model is composed of a rock block and a structural plane of a cutting rock block. Through indoor tests of the rock samples collected from the stope, the average uniaxial compressive strength of the rock block is between 60 and $80 \mathrm{MPa}$, belonging to the category of hard rock with high strength. Therefore, during the toppling failure process, it can be considered that the deformation of the rock mass mainly arises from overturning of the rock mass and the separation of the structural plane, whilst the compression, expansion, and plastic deformation of the rock mass are negligible. Based on these simulations, the properties of the on-site rock block and test block used in the indoor test are comparable. As such, physical and mechanical parameters of the rock block solid unit can be directly used as test results. The strength parameters of the rock mass are shown in Table 4. Discontinuity parameters can be estimated using Mohr Coulomb criterion. Firstly, a current slope model is established to simulate the characteristics of toppling failure under current conditions. The final state is then achieved through three excavations to obtain the slope failure characteristics following each excavation. The 3DEC model is shown in Figure 6.

According to statistical analysis of the average spacing between the rock strata structural planes (Table 4), differences in the linear density of the structural planes corresponding to different lithologies were present. To facilitate these calculations, different types of structural surfaces including slabs, joints, or fractured surfaces are no longer subdivided or classified, but structural surfaces in the same lithology are regarded as similar. For large-scale fault planes, further reductions and assignments are required. The model divides structural planes according to actual statistical data, and the distribution of structural planes within the same lithology is uniformly distributed according to linear density. The main lithology includes quaternary overburden (Q), gneiss (B3-3), andalusite schist (B3-2 and B2-1), finegrained sandstone (B3-1 and B1), and dolomite quartz schist (B2-2). 


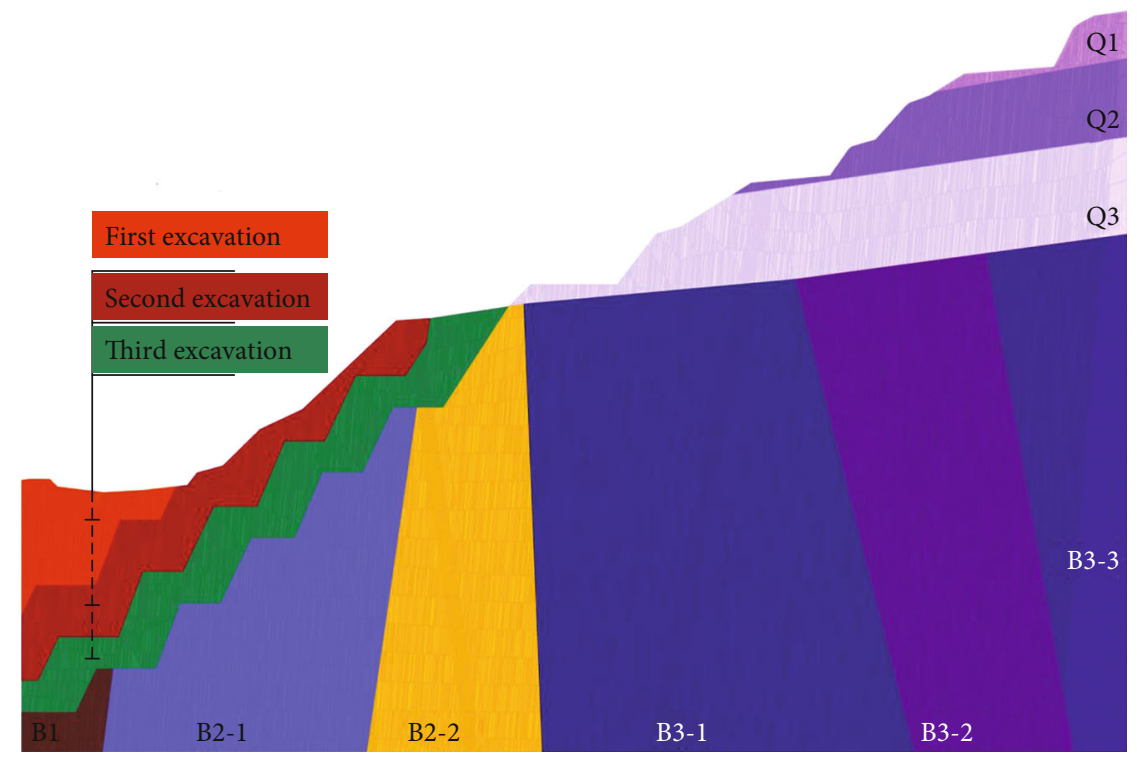

Figure 6: Typical cross section of the mining pit.

According to surveys on the lithological characteristics of the strata, the structural planes of the relevant strata show plate-like cleavage and foliation; the planes are generally closed, siliceous, and thin-filmed and are relatively straight, smooth, and easy to shear and slide along the strata. The survey analyses also showed that the structural planes in different rock bodies differ in terms of spatial distribution and physical and mechanical parameters. As such, the physical and mechanical differences of these rock strata planes should be considered during the modeling process. Specific rock mass structural plane parameters are shown in Table 5.

4.3. Simulation Analysis. The model can be divided into three excavations that range from the current to final state. The simulation uses the failure characteristics of each side of the slope following step-by-step excavations of the stope, measuring the variation in dumping failure characteristics according to the excavation depth in the form of displacement cloud diagrams. Figure 7(a) shows the slope collapse characteristics following calculations of stability under current conditions. Figure 7(b) shows the enlarged displacement cloud map of the current damage area. Compared with the actual damage position delineated in Figure 7(a), the two collapse damage positions are comparable. In addition, the failure modes show broken line failures that when compared to the actual situation, show a simulated damage depth that is relatively shallow. Changes in the dumping angle of the failure area gradually occur with the extension of the failure broken line. In the toppling head, the deflection angle of the layered rock mass is small, and the slabs can be separated once the bedding has been pulled apart, which generates random rotation or movement. The middle of the toppling failure is squeezed by the upper tensile crack plate, resulting in large bending deformation, with a maximum rotation angle of $43^{\circ}$ using the broken line as the rotation axis. In the lower toppling failure area, the slab block is squeezed by the upper rock mass, forming an antislip zone. Under strength resis- tance of the rock mass, deformation gradually decreases and the broken line gradually disappears.

Figure $7(\mathrm{c})$ shows the calculation of the displacement cloud map following the initial excavation. The excavation depth of the slope toe is $20 \mathrm{~m}$, and the maximum toppling fracture depth after calculation is $34 \mathrm{~m}$. Figure $7(\mathrm{~d})$ shows the enlarged displacement cloud map of the failure area. Compared to current conditions, the scale and depth of the damage following the excavation of the slope toe increase, but the damage location is comparable to the current situation and can be divided into three parts in terms of dumping damage. The upper area is subject to tensile fracture, and the layered rock mass produces tensile cracks along the joint plane. Once the layered rock mass in the tensile fracture section loses its constraints on both sides, bedding fractures occur. The lower area of the rock mass in the tensile fracture section breaks outwards whilst the upper region breaks inwards, causing a large downward thrust. The middle region forms the main body toppling damage zone. When the lower slope toe is excavated, antisliding forces are reduced, and the middle region forms the main body of the sliding load to produce an overall dump. The direction of dumping and the angle are uniform, with the deflection angle reaching $54^{\circ}$. The lower area represents the antisliding zone. These assessments are made based on the deviation of the deflection angle of the rock formation in this section from the middle region, which is gradually reduced, with displacement of the lower area reduced relative to the middle region. However, due to the excavation of the slope toe, the empty surface at the bottom deepens, and the empty slab loses support and falls. This results in pulling of the upper slab rock mass to aggravate the deflection.

Figure $7(\mathrm{e})$ uses the displacement cloud map following the second excavation. The excavation depth is $40 \mathrm{~m}$, and the maximum toppling fracture depth after calculation is $41.5 \mathrm{~m}$. Figure $7(\mathrm{f})$ shows the enlarged displacement cloud map of the failure area. Following the second excavation, 


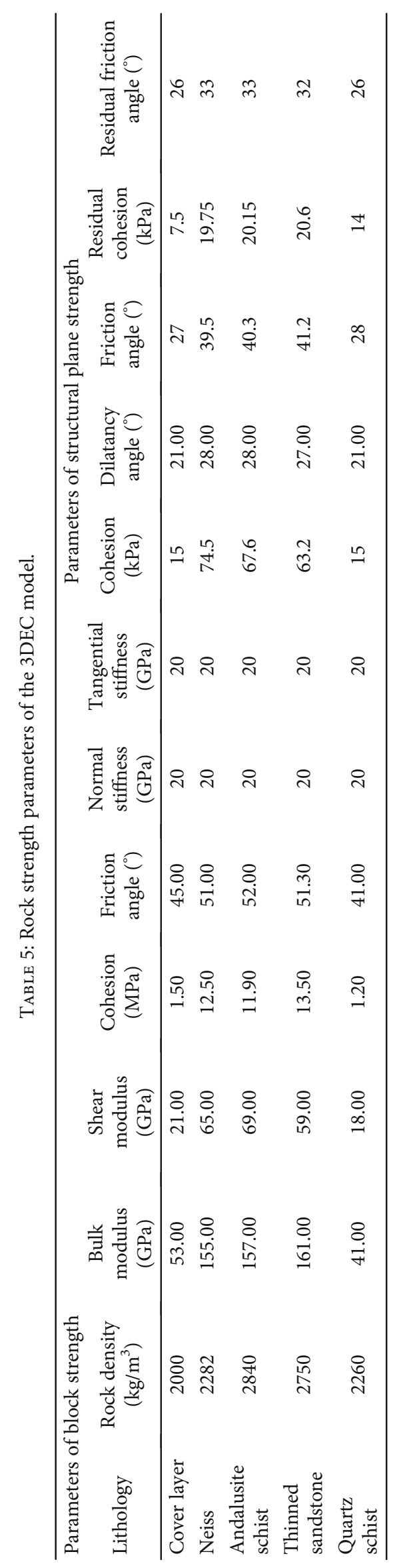


Displacement magnitude

$5.0000 \mathrm{E}+00$ $4.6000 \mathrm{E}+00$ $4.2000 \mathrm{E}+00$
$3.8000 \mathrm{E}+00$ $3.8000 \mathrm{E}+00$ $3.4000 \mathrm{E}+00$ $3.0000 \mathrm{E}+00$ $2.2000 \mathrm{E}+00$ $1.8000 \mathrm{E}+00$ $1.4000 \mathrm{E}+00$ $1.0000 \mathrm{E}+00$ $.0000 \mathrm{E}+00$ $2.0000 \mathrm{E}+00$

$.0000 \mathrm{E}+00$

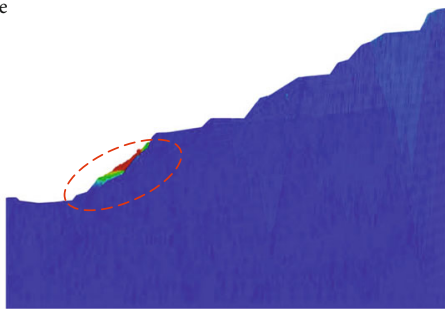

(a) Overall slope toppling failure in the current form

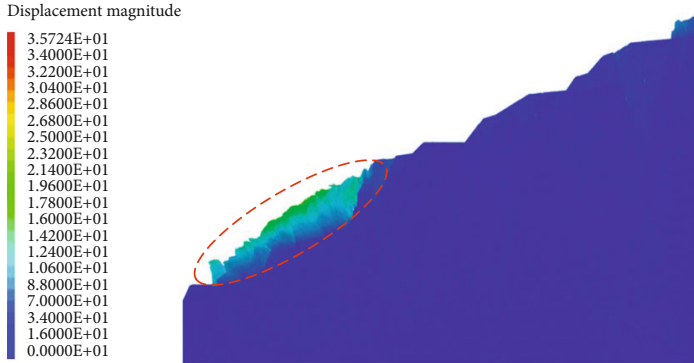

(c) Toppling failure of the first excavated slope

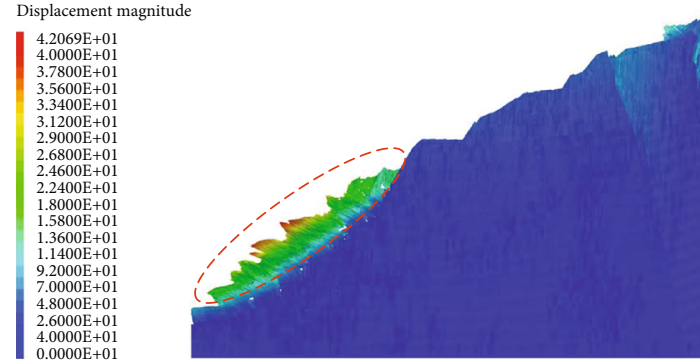

(e) Entire toppling failure of the second excavation slope

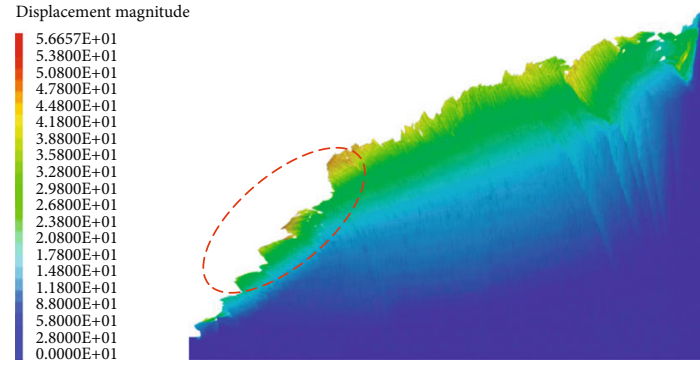

(g) Overall dumping failure of the final boundary

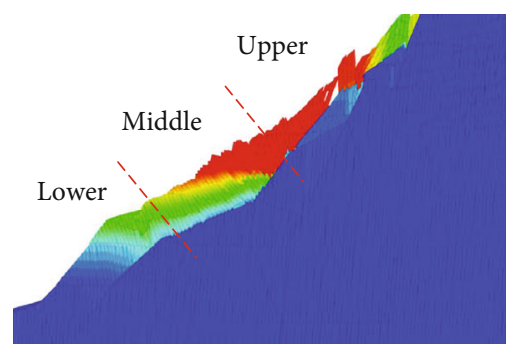

(b) Partial toppling failure of the slope in its present form

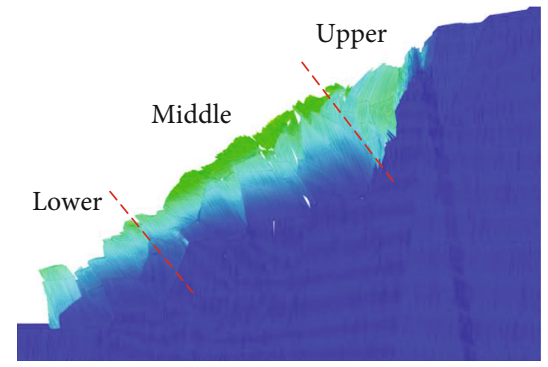

(d) Partial toppling failure of the first excavated slope

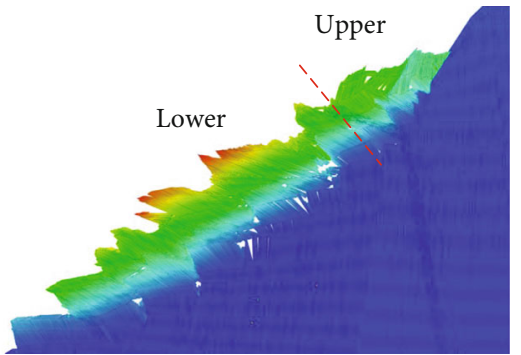

(f) Partial toppling failure of the second excavation slope

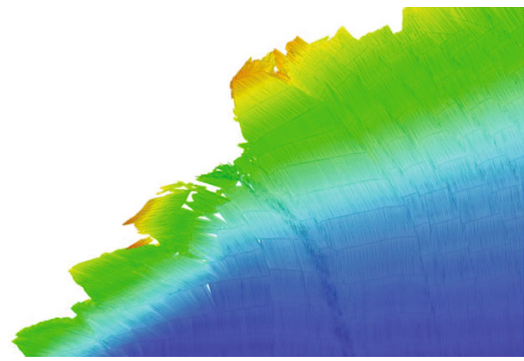

(h) Local conditions of slope toppling failure

Figure 7: Slope collapse under different excavation conditions.

the collapse damage of the slope further increases, and the breaking line of the dumping body evolves into a straight line that passes through the toe of the slope. The dumping zone can no longer identify the bottom antislip zone and can only be divided into the upper tensile fracture zone and the lower main dumping zone.

The tensile fracture area following the second excavation was similar to the shape of the initial excavation. A "<"-shaped fracture area pointing to the bottom of the slope also formed along the slope surface, but rock formation in the tensile fracture area showed bending. Different from the "bending down and bowing" dumping caused by the first excavation, the dumping body of the second excavation was similar to linear stack dumping, in which no transition sec- tion in the middle of the dumping body was observed. This was due to the bottom failing to form obvious antiskid sections. The sliding section failed to provide antiskid support for the middle of the dumping body, meaning that the dumping rock formation deflection occurred around the breaking point as the axis.

Figures $6(\mathrm{~g})$ and $6(\mathrm{~h})$ show the overall and local toppling failure of the final boundary. The excavation depth is $\sim 64 \mathrm{~m}$. After calculation, the maximum toppling fracture depth was $90 \mathrm{~m}$. The slope under the final boundary forms overall toppling, which can be divided into tension fracture and dumping sections. The dumping passes from the top to the toe of the slope. The lower region fails to form effective support, leading to formation of the antiskid section. 


\section{Conclusions}

(1) Through on-site investigations, the characteristics of toppling and failure of the high rock slope in the Southwest stope of the Taiping Mining industry in Inner Mongolia were analyzed. An obvious phenomenon of "bending waist and bowing head" was observed in the damaged rock formation, with the tilting angle of the rock formation reaching $46^{\circ}$ and the distribution density of the joint fissures reaching $7-15$ pieces $/ \mathrm{m}$. The exposed section is subject to tension dislocation along the joints, bedding, lithological interface, and other interfaces of the rock strata. The maximum buried depth of the sliding surface (tilted bending surface) was $20 \mathrm{~m}$, and the shape of the sliding surface was close to a broken line

(2) Through triaxial compressive strength tests, uniaxial compressive strength tests, and splitting tensile strength tests on the rock, the rock block had a compressive strength of $102-183 \mathrm{MPa}$, with a relatively low mineral composition. The microstructure showed dense flaky bedding and a high degree of consistency with the macro bedding of the slope. This suggested that the study area has been severely compressed by horizontal tectonic movements and that the collapse of the rock formation was mainly controlled by various types of structural surfaces

(3) Through the evaluation of regional rock integrity parameters and rock soft and hard parameters, rock mass strength in the high rock slope was estimated based on the Hoek-Brown strength estimation criterion. The rock mass strength parameters applicable to numerical calculations were obtained, providing a useful reference for future studies

(4) Using the 3DEC method, a discrete element simulation scheme based on the control of the rock mass structural planes was designed. A solid model of three stages of excavation was constructed. Through calculation and analysis, under current conditions and those of the first excavation, a crack, dump, and antisliding zone was formed. The rock formation in the crack zone forms a "<"-shaped fracture and compression along the slope surface pointed to the bottom of the slope. In the lower dumping zone, the dumping deflection angle of the dumping zone gradually increased with excavation, and the deformation range and antiskid zone gradually increased. Following the third excavation, the antislip area disappeared, and the toppling breaking line evolved from a broken to straight line. In the final state, the entire slope collapsed, with the collapse of the dumping body penetrating the top to the foot of the slope

\section{Data Availability}

The data are available and explained in this article; readers can access the data supporting the conclusions of this study.

\section{Disclosure}

On behalf of my co-authors, I declare that the work described is original research and has not been previously published.

\section{Conflicts of Interest}

The authors declare no conflict of interest.

\section{Authors' Contributions}

The manuscript was approved for publication by all authors.

\section{Acknowledgments}

This study was supported by the Research and Development of Object-Oriented Photogrammetry by UAV (Unmanned Aerial Vehicle) and Rapid Deployment Monitoring and Early Warning Equipment on High-Steep Slope (2019YFC1509604), Dazu District Science and Technology Commission Project Funding (No. DZKJ, 2018ABB1011), the National Natural Science Foundation of China (NSFC) (41941018), and Liaoning Science and Technology Project (2019JH8/10300107 and 2020JH2/10300100).

\section{References}

[1] A. Braathen, L. H. Blikra, S. S. Berg, and F. Karlsen, "Rockslope failures in Norway; type, geometry, deformation mechanisms and stability," Norwegian Journal of Geology, vol. 1, no. 84, pp. 67-88, 2004.

[2] Y. Wang, B. Zhang, S. H. Gao, and C. H. Li, "Investigation on the effect of freeze-thaw on fracture mode classification in marble subjected to multi-level cyclic loads," Theoretical and Applied Fracture Mechanics, vol. 111, article 102847, 2021.

[3] G. X. Tu and H. Deng, "Characteristics of a deep-seated flexural toppling fracture and its relations with downcutting by the Lancang River: a case study on a steeply dipping layered rock slope, Southwest China," Engineering Geology, vol. 275, article 105754, 2020.

[4] Z. Li, H. X. Liu, Z. L. Dun, L. W. Ren, and J. J. Fang, "Grouting effect on rock fracture using shear and seepage assessment," Construction and Building Materials, vol. 242, article 118131, 2020.

[5] C. Cao, X. Pu, Z. Zhao, G. Wang, and H. Du, "Experimental investigation on wellbore strengthening based on a hydraulic fracturing apparatus," Journal of Energy Resources Technology, vol. 140, no. 5, 2018.

[6] Q. Meng, H. Wang, M. Cai, W. Xu, X. Zhuang, and T. Rabczuk, "Three-dimensional mesoscale computational modeling of soil-rock mixtures with concave particles," Engineering Geology, vol. 277, article 105802, 2020.

[7] X. J. Yang, J. M. Wang, D. G. Hou, C. Zhu, and M. C. He, "Effect of dry-wet cycling on the mechanical properties of rocks: a laboratory-scale experimental study," Processes, vol. 6, no. 10, p. 199, 2018.

[8] Q. X. Meng, L. Yan, Y. L. Chen, and Q. Zhang, "Generation of numerical models of anisotropic columnar jointed rock mass using modified centroidal voronoi diagrams," Symmetry, vol. 10, no. 11, 2018. 
[9] Z. G. Tao, C. Zhu, X. H. Zheng et al., "Failure mechanisms of soft rock roadways in steeply inclined layered rock formations," Geomatics, Natural Hazards and Risk, vol. 9, no. 1, pp. 1186-1206, 2018.

[10] Z. G. Tao, Z. Zhu, W. S. Han et al., "Static tension test and the finite element analysis of constant resistance and large deformation anchor cable," Advances in Mechanical Engineering, vol. 10, no. 12, 2018.

[11] C. Zhu, X. D. Xu, W. R. Liu et al., "Softening damage analysis of gypsum rock with water immersion time based on laboratory experiment," IEEE Access, vol. 7, pp. 125575-125585, 2019.

[12] H. Y. Pan, D. W. Yin, N. Jiang, and Z. G. Xia, "Crack initiation behaviors of granite specimens containing crossing-doubleflaws with different lengths under uniaxial loading," Advances in Civil Engineering, vol. 2020, Article ID 8871335, 13 pages, 2020.

[13] Z. G. Tao, C. Zhu, M. C. He, and M. Karakus, "A physical modeling-based study on the control mechanisms of negative Poisson's ratio anchor cable on the stratified toppling deformation of anti- inclined slopes," International Journal of Rock Mechanics and Mining Sciences, vol. 138, article 104632, 2021.

[14] Y. Wang and B. Zhang, "Investigation on the effect of freezethaw on fracture mode classification in marble subjected to multi-level cyclic loads," Theoretical and Applied Fracture Mechanics, vol. 111, article 102847, 2021.

[15] D. W. Yin, S. J. Chen, Y. Ge, and R. Liu, "Mechanical properties of rock-coal bi-material samples with different lithologies under uniaxial loading," Journal of Materials Research and Technology, vol. 10, pp. 322-338, 2021.

[16] C. X. Chen, Y. Zheng, and C. Y. Sun, “An analytical approach on flexural toppling failure of counter-tilt slopes of layered rock," Chinese Journal of Rock Mechanics and Engineering, vol. 35, no. 11, pp. 2174-2187, 2016.

[17] N. Li, S. F. Guo, and X. C. Yao, "Further study of stability analysis methods of high rock slopes," Rock and Soil Mechanics, vol. 39, no. 2, pp. 397-416, 2018.

[18] Y. H. Song, M. Q. Huang, M. Sun, and S. F. Guo, "Application of finite elements with joint net to stability analysis of toppling slope," Rock and Soil Mechanics, vol. 32, no. 4, pp. 1205-1210, 2011.

[19] Z. Liu, B. Miao, and C. C. Wang, "Stability analysis of jointed rock slopes based on discrete element method," Rock and Soil Mechanics, vol. 7, pp. 2199-2204, 2011.

[20] B. J. Yang, J. He, and G. Ji, "Stability analysis of slidingtoppling complex failure of rock slope," Rock and Soil Mechanics, vol. 35, no. 8, pp. 2335-2341, 2014.

[21] M. Amini, A. Majdi, and O. Aydan, "Stability analysis and the stabilisation of flexural toppling failure," Rock Mechanics and Rock Engineering, vol. 42, no. 5, pp. 751-782, 2009.

[22] A. Majdi and M. Amini, "Analysis of geo-structural defects in flexural toppling failure," International Journal of Rock Mechanics and Mining Sciences, vol. 48, no. 2, pp. 175-186, 2011.

[23] H. Q. Chen and R. Q. Huang, "Stress and flexibility criteria of bending and breaking in acounter tendency layered slope," Journal of Engineering Geology, vol. 12, no. 3, pp. 243-246, 2004.

[24] Y. Cai, Y. Mitani, and T. Esaki, "Numerical analysis of stability for an antidip stratified rock slope," Chinese Journal of Rock Mechanics and Engineering, vol. 27, no. 12, pp. 2517-2522, 2008.
[25] H. Haghgouei, A. R. Kargar, M. Amini, and K. Esmaeili, “An analytical solution for analysis of toppling-slumping failure in rock slopes," Engineering Geology, vol. 265, article 105396, 2020.

[26] M. L. Dong, F. M. Zhang, J. Q. Lv, M. J. Hu, and Z. N. Li, "Study on deformation and failure law of soft-hard rock interbedding toppling slope base on similar test," Bulletin of Engineering Geology and the Environment, vol. 79, no. 9, pp. 4625-4637, 2020.

[27] Z. Li, H. Zhou, D. W. Hu, and C. Q. Zhang, "Yield criterion for rocklike geomaterials based on strain energy and CMP model," International Journal of Geomechanics, vol. 20, no. 3, article 04020013, 2020.

[28] C. Zhu, M. C. He, M. Karakus, X. B. Cui, and Z. G. Tao, "Investigating toppling failure mechanism of anti-dip layered slope due to excavation by physical modelling," Rock Mechanics and Rock Engineering, vol. 53, no. 11, pp. 50295050, 2020.

[29] H. B. Li, Y. X. Lv, Y. Q. Liu, J. R. Li, W. S. Yao, and W. G. Qiao, "Seismic response of the stratified anti-dip rock slope," Disaster Advances, vol. 6, pp. 204-213, 2013.

[30] W.-R. Liu, J.-K. Liu, and C. Zhu, "Multi-scale effect of acoustic emission characteristics of 3D rock damage," Arabian Journal of Geosciences, vol. 12, no. 22, 2019.

[31] G. X. Yang, S. W. Qi, F. Q. Wu, and Z. F. Zhan, "Seismic amplification of the anti-dip rock slope and deformation characteristics: a large-scale shaking table test," Soil Dynamics and Earthquake Engineering, vol. 115, pp. 907-916, 2018.

[32] Z. Li, J. A. Wang, L. Li, L. X. Wang, and R. Y. Liang, "A case study integrating numerical simulation and GB-InSAR monitoring to analyze flexural toppling of an anti-dip slope in Fushun open pit," Engineering Geology, vol. 197, pp. 20-32, 2015.

[33] C. Shi, D. J. Li, W. Y. Xu, and R. B. Wang, "Discrete element cluster modeling of complex mesoscopic particles for use with the particle flow code method," Granular Matter, vol. 17, no. 3, pp. 377-387, 2015.

[34] X. D. Chen and H. F. Wang, "Slope failure of noncohesive media modelled with the combined finite-discrete element method," Applied Sciences, vol. 3, no. 9, 2019.

[35] S. Lin, C. M. Lo, and Y. C. Lin, "Investigating the deformation and failure characteristics of argillite consequent slope using discrete element method and Burgers model," Environmental Earth Sciences, vol. 76, no. 2, 2017.

[36] M. Weng, T. C. Chen, and S. J. Tsai, "Modeling scale effects on consequent slope deformation by centrifuge model tests and the discrete elementmethod," Landslides, vol. 14, no. 3, pp. 981-993, 2017.

[37] W. Zhou, W. Yuan, G. Ma, and X. L. Chang, "Combined finitediscrete element method modeling of rockslides," Engineering Computations, vol. 5, no. 33, pp. 1530-1559, 2016.

[38] Y. Lu, Y. Tan, and X. Li, "Stability analyses on slopes of clayrock mixtures using discrete element method," Engineering Geology, vol. 244, pp. 116-124, 2018.

[39] G. J. Xu, K. Z. Zhong, J. W. Fan, Y. J. Zhu, and Y. Q. Zhang, "Stability analysis of cohesive soil embankment slope based on discrete element method," Journal of Central South University, vol. 27, no. 7, pp. 1981-1991, 2020.

[40] N. X. Xu, J. Y. Zhang, H. Tian, G. Mei, and Q. Ge, “Discrete element modeling of strata and surface movement induced by mining under open-pit final slope," International Journal 
of Rock Mechanics and Mining Sciences, vol. 88, pp. 61-76, 2016.

[41] O. Katz, J. K. Morgan, E. Aharonov, and B. Dugan, "Controls on the size and geometry of landslides: Insights from discrete element numerical simulations," Geomorphology, vol. 220, pp. 104-113, 2014.

[42] Z. Li, S. G. Liu, W. T. Ren, J. J. Fang, Q. H. Zhu, and Z. L. Dun, "Multiscale laboratory study and numerical analysis of waterweakening effect on shale," Advances in Materials Science and Engineering, vol. 2020, Article ID 5263431, 14 pages, 2020.

[43] L. L. Yang, W. Y. Xu, Q. X. Meng, and R. B. Wang, "Investigation on jointed rock strength based on fractal theory," Journal of Central South University, vol. 24, no. 7, pp. 1619-1626, 2017.

[44] C. Zhu, Z. H. Yan, Y. Lin, F. Xiong, and Z. Tao, "Design and application of a monitoring system for a deep railway foundation pit project," IEEE Access, vol. 7, pp. 107591-107601, 2019.

[45] Q. X. Meng, H. L. Wang, W. Y. Xu, and Q. Zhang, “A coupling method incorporating digital image processing and discrete element method for modeling of geomaterials," Engineering Computations, vol. 35, no. 1, pp. 411-431, 2018.

[46] Q. X. Meng, H. L. Wang, W. Y. Xu, M. Cai, J. R. Xu, and Q. Zhang, "Multiscale strength reduction method for heterogeneous slope using hierarchical FEM/DEM modeling," Computers and Geotechnics, vol. 115, article 103164, 2019.

[47] C. H. Wang and M. C. He, "Latest Hoek-Brown rock mass streng the estimation method and its application," Journal of XI'AN University of Science and Technology, vol. 26, no. 4, pp. 456-464, 2006.

[48] D. B. Wu and W. Y. Xu, "Hoek-Brown criterion-based study on mechanical parameters of excavated slope rock masses," Journal of Hohai University (Natural Sciences), vol. 33, no. 1, pp. 89-93, 2005.

[49] G. T. Meng, D. Fang, and L. Q. Li, "Study of equivalent strength parameters of ubiquitous joint model for engineering rock mass with preferred intermittent joints," Chinese Journal of Rock Mechanics and Engineering, vol. 32, no. 10, pp. 21152121, 2013.

[50] K. Z. Xia, C. X. Chen, and X. M. Liu, "Estimation of rock mass mechanical parameters based on ultrasonic velocity of rock mass and hoek-brown criterion and its application to engineering," Chinese Journal of Rock Mechanics and Engineering, vol. 32, no. 7, pp. 1458-1466, 2013.

[51] Q. X. Meng and W. Wang, "A novel closed-form solution for circular openings in generalized Hoek-Brown media," Mathematical Problems in Engineering, vol. 2014, Article ID 870835, 7 pages, 2014. 